\title{
ARTIGO
}

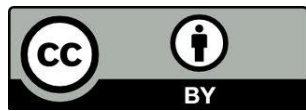

\section{REFLEXÕES SOBRE OS CONCEITOS DE ENSINO RELIGIOSO E ORIENTAÇÃO ESPIRITUAL COM CRIANÇAS E JOVENS}

\author{
Reflections on the concepts of Religious Teaching and Spiritual Orientation with \\ children and young people
}

Júlia M. C. Motta

Psicóloga, doutora em Saúde Coletiva pela FCM-DMPS- UNICAMP, com pós-doutorado em Psicologia Social pela PUCSP Professora no IDH- Porto Alegre. Professora convidada na Universidade de Havana, Cuba. juliacmotta@gmail.com

Edison S. Neves Médico homeopata, mestre da Sede Geral da União do Vegetal,responsável geral da Orientação Espiritual com crianças e jovens da UDV e da lista on line específica deste trabalho no Centro Espírita Beneficente União do Vegetal(CEBUDV) edisneves@Yahoo.com.br

\begin{abstract}
RESUMO: O presente trabalho visa discutir os conceitos de ensino religioso e orientação espiritual com crianças, adolescentes e jovens, evidenciando as confusões conceituais encontradas em artigos brasileiros e estrangeiros sobre o tema. Após uma pesquisa preliminar, desenvolvida pelos autores em uma instituição religiosa brasileira, o CEBUDV - Centro Espírita Beneficente União do Vegetal, também conhecida por UDV, União do Vegetal, verificou-se também pouca clareza conceitual entre os participantes desta sociedade religiosa. A partir dos resultados, foi feito um trabalho com pais e responsáveis institucionais sobre esses conceitos, resultando no clareamento conceitual e pela escolha da terminologia Orientação Espiritual com crianças, adolescentes e jovens na UDV.
\end{abstract}

Palavras-chave: Orientação espiritual, ensino religioso, UDV-União do Vegetal, pesquisa institucional.

ABSTRACT: The present work intends to discuss the concepts of religious education and spiritual orientation with children and teenagers, displaying the conceptual misunderstandings found in Brazilian and foreigners articles about the theme. After a preliminary research, developed by the authors in a Brazilian religious institution, the CEBUDV - Centro Espírita Beneficente União do Vegetal, also known as UDV, União do Vegetal, it was verify to exist little conceptual clarity between the participants of this spiritual practice. Within the results, it was done a work with the parents and institutional representatives about these concepts, resulting in conceptual understandings and in the selection of the terminology spiritual orientation with children and teenagers in the UDV.

Keywords: Spiritual orientation, Religious education, UDV-União do Vegetal, Institutional research. 


\section{Introdução}

O Ensino Religioso e a Orientação Espiritual com crianças e jovens são abordagens bastante comuns entre as religiões ocidentais, em especial, as cristãs. Entretanto, ao estudar o tema em periódicos especializados, encontramos, com certa frequência, um uso indistinto dos dois termos, outras vezes, uma conceituação pouco clara.

Entre 2009-2010, os autores desenvolveram uma pesquisa preliminar no CEBUDV - Centro Espírita Beneficente União do Vegetal, também conhecido como UDV, sobre 'ensino religioso para crianças e adolescentes'. Essa investigação teve como objetivo central pesquisar entre os sócios da UDV, na faixa etária entre 18-35 anos, que viveram a infância e/ou adolescência na instituição, como eles narram a experiência vivida. Buscamos saber com esses sujeitos quais as lembranças de atividades vivenciadas na instituição que foram significativas.

Os objetivos principais foram gerar informações avaliativas sobre histórias de pessoas que passaram a infância e adolescência na UDV. Com isso, fornecer material de reflexão para as equipes atuais, compostas de pais e responsáveis institucionais, que desenvolvem esse projeto. Também criar conhecimentos sobre o tema, contribuindo com o campo educacional de religião e sociedade. Consideramos oportunas as reflexões sobre conceitos importantes na definição do método e da metodologia usados na formação da dimensão religiosa e espiritual da identidade de crianças e adolescentes.

\section{Apresentando o conflito evidenciado pela pesquisa sobre os conceitos e as perguntas que gerou:}

Dentre os resultados da investigação feita, encontramos um conflito entre os dois conceitos: ensino religioso e orientação espiritual (Motta, Neves, Almeida, Rodrigues,2011). Ora os conceitos eram usados como se fossem sinônimos, ora eram apresentados como opostos. Esta confusão conceitual criava também pouco discernimento do conceito filosófico de homem para pedagogia de trabalho. Como formar a dimensão espiritual da identidade das crianças e adolescentes sem clareza dos conceitos básicos?

A nova etapa foi buscar em artigos publicados sobre o tema como esta distinção nos conceitos estava posta. Após uma busca sistemática em periódicos nacionais e 
internacionais sobre religião, educação e sociedade, foi encontrada com frequência a mesma confusão no uso desses conceitos: ensino religioso e orientação espiritual. Algumas vezes, aparecem como sinônimos. Outras vezes, é descrita no corpo do texto uma ação prática nos moldes de ensino religioso, entretanto, o mesmo é a seguir denominado como orientação espiritual e vice-versa. Daí a pergunta norteadora: como esta confusão entre tais conceitos foram se formando na história brasileira?

\section{Historiando brevemente a chegada e instalação do movimento de educação de crianças e jovens no país:}

No Brasil, desde o período da colonização, encontra-se a presença de grupos religiosos católicos encarregados da educação dos filhos das famílias abastadas, inaugurando o ensino privado no país. Data desse período o costume de muitos pais de deixar entregue aos religiosos a responsabilidade pela educação intelectual e espiritual dos filhos, sem uma participação compartilhada entre pais e religiosos. Estado e Igreja governavam o país de comum acordo. A responsabilidade educacional esteve transferida aos religiosos, que ditavam os padrões de certo e errado, bom e mal. Os pais colonizadores da época repetiam em casa os padrões estabelecidos pelos religiosos, sem se darem o direito de questionar os valores postos pelos religiosos nas escolas primárias.

Enquanto isto, as religiões africanas tiveram que sofrer uma adaptação, onde associavam seus orixás aos santos católicos, em um esforço de conquistar espaço e respeito às suas práticas. Com a Lei Áurea (1888), teoricamente, os escravos tornaramse cidadãos, com certo direito a exercer seus rituais religiosos.

Relembrando a $1^{\text {a }}$ Constituição brasileira, pós Independência do Brasil (1822), foi organizado um grupo constituinte onde haviam 24 padres deputados. Na Carta Magna ficou definido que a religião oficial do país era a Igreja Católica Apostólica Romana. Demais igrejas ficaram restritas à cultos domésticos. Ou, a saída dos escravos que mesclaram seus orixás com santos oficiais.

Com a Proclamação da República (1889), criou-se a $1^{\text {a }}$ Constituição (1891) da era republicana tornando a nação laica, apesar das resistências da Igreja Católica. Mas a Igreja Católica passou a reivindicar o retorno do seu poder perdido. Na Constituição de 1934 ela obteve algumas vitórias, como o retorno da autorização para o ensino religioso católico nas escolas, a possibilidade de casamento religioso com validade civil e a abertura para "colaboração" entre Estado e Igreja (Giumbelli, 2008). A partir dessa 
Constituição, o Brasil passou a ser uma nação religiosa pluralista.

Durante as primeiras décadas do século XX, o Brasil, apesar de se dizer um país religioso pluralista, viveu uma quase hegemonia religiosa da Igreja católica, dominando o calendário comemorativo nacional, misturando eventos civis e religiosos. Nas repartições públicas, nas escolas, nos rituais de casamento, batizados e encomenda das almas, preparação para a morte, todas as cerimônias oficiais permaneceram católicas. Outras religiões eram vistas com cautela ou desconsideradas. Será deste período o habitus dos brasileiros de se declararem 'católicos não praticantes'? Qual a diferença entre esse recurso e o dos escravos em produzirem um sincretismo religioso, dando aos orixás nomes de santos católicos? É possível ler aqui uma saída, um ‘jeitinho brasileiro’ de driblar a censura de uma religião única?

Na segunda metade do século, durante a ditadura militar (1964-1986), o Brasil viveu vários movimentos de organizações alternativas à situação de falta de liberdade de expressão. Um destes recursos foi a expansão de outras propostas de psicologia clínica diferentes da psicanálise, e a chegada da psicoterapia de grupo. Como exemplo, as organizações profissionais se estabelecerem em federações, associações e sociedades. Alguns desses grupos chegaram a se tornar 'pequenas igrejinhas', notadamente no campo da psicologia. Também as religiões alternativas ao catolicismo conquistaram espaço, pondo em questionamento as verdades ideológicas plantadas. Para outro setor social, as igrejas foram espaços alternativos de resistência à ditadura.

A partir deste período que alguns questionamentos ganharam voz com relação à educação religiosa católica obrigatória nas escolas públicas. A busca pelo fim da ditadura gerou muitos frutos, sendo um deles, a proposta ecumênica dos rituais comemorativos públicos. Padres, pastores, pais de santo, monges, espíritas, puderam se irmanar, compartilhando suas propostas e ideais de mundo. Como disseram Freire \& Faundes (1985:27), “a tolerância ao diferente é o princípio da democracia”.

Dando um salto na história, chega-se às décadas de 1980-90 e à instalação do domínio da mídia e da TV, que modifica o conceito de educação e o lugar dos pais neste processo. Seguido pelo movimento de globalização, que teve início no mundo do trabalho, e se estendeu aos demais setores sociais; e, finalmente, a popularização do computador e da internet, que propaga numa velocidade vertiginosa as informações, ditando valores, criando uma nova ética em um novo mundo virtual. Para muitos, 
poder-se-á dizer que o mundo virtual se transformou numa espécie de religião, com um deus ex-machina.

Enquanto estes fenômenos foram acontecendo, muitos pais permaneceram submissos aos ditames do Estado/igreja de como educar seus filhos quanto à noção de divindade, conceitos de mundo e vida, de certo e errado.

Esse fato social vem crescendo no país de forma considerável nas últimas décadas, de forma especial com os pentecostais e os católicos carismáticos, dentre outros grupos. Tal fenômeno deixa dúvidas se esses pais estão optando por um caminho ou se submetendo ao poder verticalizado dos religiosos, reproduzindo o período da colonização brasileira. São necessárias outras pesquisas para esclarecer a dúvida sobre o que está crescendo no país: submissão ou opção por continuidade religiosa? Por exemplo, algumas das futuras pesquisas poderiam iniciar traçando perfis religiosos familiares com seus desdobramentos no espaço institucional escolar.

A crescente formação de novas propostas religiosas atrai segmentos sociais diversos. Algumas respondem às inquietações dos menos favorecidos, econômica e educacionalmente. Outras atraem segmentos sociopolíticos e econômicos distintos. Diferentes motivações podem estar na base do fenômeno, como a busca por um grupo de referência, quando o modelo social se apresenta em crise, ou o despertar para a dimensão espiritual e religiosa na formação identitária do ser humano, dentre outras possibilidades. Muitas perguntas e poucas respostas, ainda. Dentre elas, o que representa a orientação espiritual com crianças e jovens, e o que representa o ensino religioso nas mesmas fases do desenvolvimento?

Clarear o conceito básico de trabalho da dimensão espiritual ou religiosa com criança e jovens é definir os critérios éticos e morais, códigos de fidelidade e lealdade, critérios de vinculação entre seres humanos e a natureza, o que torna as pessoas mais participativas nos processos de transformações sociais.

\section{Buscando outras definições dos conceitos em periódicos}

A construção da identidade é responsável pela constituição de modelos de convivência. Em tempos de sociedade plural, a inserção de jovens com vivência em comunidades religiosas na infância e adolescência é facilitadora ou não na formação de uma identidade mais saudável? 
Aqui, o conceito de sociedade plural representa um cenário em constante mudança, onde se espera que a construção da identidade seja um trabalho da vida toda, não mais uma característica atribuída ou imposta por outros. Hoje, é um tempo-espaço coletivo onde alguns sinalizadores identitários foram destruídos, marcos históricos desvalidados, e a velocidade da disseminação das informações acelerada pela chegada do computador, das novas mídias e da internet. Do sujeito pós-moderno se espera correspondência à sociedade plural, que seja também consolidada numa identidade plural, sempre transitória, sempre em construção.

Fala-se "em identidade nacional, identidades étnicas, mas nunca as identidades religiosas são contempladas nas análises" (Miranda, 2010: 128). O autor chama a atenção para a identidade religiosa, não espiritual. Para construção da dimensão religiosa ou espiritual da identidade de uma criança e do adolescente, é preciso saber que tipo de sociedade aquele grupo familiar ou religioso está querendo formar. Quanto mais os pais se envolverem com o assunto, mais descobrirão que são os responsáveis principais por este trabalho. Essa descoberta revela a necessidade de estudar, refletir e compartilhar com outras pessoas, para serem os protagonistas conscientes do que querem refletir com os filhos.

Algumas pesquisas tratam desse tema, como aquela realizada por Hervien-Léger (1999), citado por Miranda (2010: 128), quando propõe que os processos de identificação religiosa na sociedade moderna pode ser visto como passando por livre comunicação de quatro dimensões típicas de identificação: comunitária, ética, emocional e cultural. Explica o autor sua proposta como sendo a dimensão comunitária o particular, o local, o singular das pessoas; a consciência individual e os valores universais formam a ética; a consciência afetiva se refere à percepção do eu, à dimensão emocional; saberes, modos de fazer e memória do grupo constituem a dimensão cultural. Apesar de propor uma classificação muito próxima do que aqui é visto como espiritual, o autor usa o termo dimensão religiosa.

Afinada com essa teoria citada acima, Pires (2010) diz que alguns pesquisadores divergentes do seu ponto de vista sobre o campo da educação religiosa afirmam não ser possível estudar o fenômeno da aquisição de identidade religiosa por crianças, tendo como sujeitos as próprias crianças. Mostra com sua pesquisa, a partir de desenhos e conversas com crianças, que é possível estudar a faceta religiosa na formação das 
crianças, a partir de suas falas. Propõe que é necessário não traduzir as crianças, mas estudar, respeitando seu processo, que não é o mesmo do adulto. Novamente, aparece a dimensão religiosa como foco da pesquisa, e não a espiritual, apesar da autora descrever a necessidade de "respeitar o processo da criança sem traduzi-la", o que caracteriza, segundo a conceituação apresentada aqui, a dimensão espiritual.

Para a criança, o conteúdo simbólico das religiões não está em jogo. Ao contrário, o que está em jogo é o conjunto de atividades envolvidas no frequentar a sociedade religiosa. Para a criança, não importa com quem vai ao ambiente comunitário, mas com quem se relaciona durante o tempo em que está nesse coletivo, e quais atividades fazem juntos. A centralidade do lúdico como forma de aprendizagem e de sociabilidade é mantida nesse contexto (Motta et al, 2011).

As sociedades iletradas e as crianças guardam uma fidelidade ao processo integrado de construção da socialização e aprendizagem religiosa e espiritual, sem separar os contextos religiosos e espirituais dos sociais. Para a criança, conhecer é viver, experimentar. O que importa é o jogo vivencial em si, a experimentação, e não o simbolizado a partir do vivido. O jogo, o lúdico, encerra em si sua gratificação, dispensando outras possibilidades elaborativas (Motta, 2002).

Retomando a pesquisa de Pires (2010), os pais no grupo pesquisado não deixam as crianças frequentarem outras comunidades religiosas porque, para eles, o ato de ir à igreja implica o aprendizado de um conjunto de ensinamentos teológicos de uma fé em particular. Os pais, sabendo que as religiões divergem sobre as abordagens do fenômeno religioso, sentem-se ameaçados na sua fé, ao autorizar os filhos a conhecer outras propostas. Para Pires, “à medida que a criança cresce, a prática vai se tornando subordinada ao seu significado". Isto quer dizer que o sentir da vivência passa a dar lugar ao pensar religioso simbolizado. Nessa pesquisa, a autora estuda a dimensão religiosa dos pais e sua escolha em transmitir aos filhos esta opção. Nesta pesquisa de Pires, o posicionamento familiar interfere na liberdade das escolas quanto a educação religiosa dos filhos.

Em outro trabalho, com um grupo de jovens púberes na Alemanha, Arndt et al (2010) descrevem que os sujeitos da pesquisa apreciavam a interação da consciência, a compaixão, a generosidade, a sabedoria e a aspiração pelo belo, em particular a orientação religiosa e a crença em Deus. Os autores afirmam que esses aspectos crescem 
com o amadurecimento dos jovens. Mas, não explicam como se dá esse crescimento com a idade. Os jovens alemães da pesquisa, assim como os pesquisados por Pires no Brasil, revelam que há uma troca da prática pelo significado, do viver ao pensar religioso. Novamente a dimensão religiosa, e não a espiritual, é o foco no estudo com jovens na Alemanha.

Já Bethani e Qi Wanq (2008), descrevendo seus achados em pesquisa qualitativa, afirmam que o desenvolvimento espiritual infantil habilita maior proteção no enfrentamento em situações de guerra e mudanças forçadas. Consideram a religiosidade como uma dimensão cultural que tem efeitos positivos na formação identitária, individual e coletiva. Nessa pesquisa, os autores usam o termo dimensão espiritual como recurso no enfrentamento de situações extremadas, entretanto, não conceituam a denominação.

Resultados parecidos são encontrados em Sturla Sagbert (2008), quando diz que a espiritualidade vem crescendo em muitos domínios da Noruega, entretanto, isso não tem tido reflexos na educação pública. Discute o porquê do fato, sugerindo algumas abordagens hermenêuticas para entender a espiritualidade. Propõe que há necessidade de incluir educação espiritual na vida escolar, uma vez que considera central a presença da criança em lugares sagrados. Entende a espiritualidade como aprendizado cultural. Para o autor, a espiritualidade na infância auxilia o adulto a explorar e rearticular aquilo em que ele acredita: o que é o ser humano, e a importância da espiritualidade no cultivo da esperança. Aqui, a proposta é por uma orientação espiritual, e não religiosa, para jovens e crianças.

Outra pesquisa, agora apresentada por Raisuyah Bhagwan (2008), defende que o bem-estar espiritual forma uma importante dimensão global das crianças/jovens no enfrentamento das vulnerabilidades ao longo da vida. Por isso, sua pesquisa explora a espiritualidade das crianças/jovens e a diversidade de caminhos que os educadores praticantes de uma religião podem seguir ao trabalhar com elas. Defende que a pedagogia utilizada ilumina, além do grupo e do indivíduo, as histórias contadas, os rituais, dramas, as artes e poéticas vividas, delineando a comunidade e sua espiritualidade, isto é, traduzem o coletivo, enquanto inserem as crianças e os jovens. A escolha é por orientação espiritual, e não ensino religioso.

Numa pesquisa sobre o conceito de Deus realizada em escola pública 
fundamental na Holanda, tendo como sujeitos indígenas e imigrantes, Avest (2009) encontrou uma idéia de Deus multirreligiosa nos grupos sociais formados por etnias diversas, mostrando que a dimensão espiritual é cultural e depende do átomo social do grupo, ou seja, é uma construção.

Já na Inglaterra, Freathy e Aylward (2010) examinam por que as crianças e jovens têm dificuldades em entender o conceito Jesus, baseado em milagres, ressurreição e status de filho de Deus. Para esse grupo estudado, entender e acreditar se confundem e ficam na dependência de como a educação religiosa é feita. Alguns sujeitos admitiram que acreditar é condição para entender. Interessante a questão levantada pelo autor, quanto a entender e acreditar. Para uma educação religiosa baseada em transmissão de verdades, acreditar é base para compreender; entretanto para uma orientação espiritual baseada em valores éticos e morais de uma cultura, não há essa dependência e sim a necessidade de reflexão.

Novamente, reaparece um conceito de identidade religiosa transmitida, herdada do grupo adulto, onde estão as crianças e os jovens sem possibilidades para uma identidade construída, refletida para ser incorporada como opção. Consideramos que uma identidade consciente somente é adquirida se for baseada em reflexões, mais facilmente encontrada na orientação espiritual do que na religiosa, segundo as reflexões que estamos desenvolvendo.

Em Israel, Sagberg (2008) desenvolveu uma investigação com dois grupos: um de jovens e crianças e outro de idosos. A pesquisa foi apoiada na teoria de Erikson. Esse estudo visou conhecer aspectos da formação da identidade do ego, baseados em duas variáveis multidimensionais, da religião e não religião individual. A caracterização de cada grupo resultou na evidenciação de que todos tinham uma vivência religiosa, que aparecia nas identidades construídas.

Estudando sua ação com crianças e jovens na Libéria, durante o período da guerra civil, o pastor Emile (2008), da igreja Batista, compartilha que, no abismo da guerra, ouvir as crianças sobre seus interesses e responsabilidades é uma terapêutica eficiente. O propósito do artigo é recomendar esse simples processo e sugerir que escutem as crianças e os jovens contarem suas histórias e dividirem seus sonhos construtivamente, interagindo com seus valores pessoais e grupais. Ao se sentirem percebidos e confirmados, essas crianças e jovens saem da impotência de estar numa 
comunidade forçada a lutar entre si.

O jogo, o brincar, para crianças e adolescentes, é primordial no desenvolvimento de sua identidade, de sua autoestima, de inclusão a um grupo. Também durante uma guerra, crianças e jovens se valem do lúdico, dos recursos imaginativos, visando a manter suas identidades saudáveis, o que fica facilitado quando existe um olhar espiritualizado do mundo e da vida.

Voltando à revisão dos artigos, Hodder (2009), na Austrália, encontrou em sua investigação que os sujeitos entrevistados se sentiam entre duas categorias: a Nova Era e os Evangélicos. Concluiu que os dois sistemas apresentam benefícios e desafios em termos do bem-estar dos jovens. Através da lente da espiritualidade, os sujeitos pesquisados ampliavam o interesse pelo comunitário. Esse fato tem importantes implicações, ao inter-relacionar o bem-estar individual com o coletivo. Entretanto, o autor não deixa claro o que chama de religioso e de espiritual. Mas, mostra a importância deste recurso no enfrentamento das adversidades sociais.

Também encontramos em Gustav Yeung e Chou (2010) um estudo realizado em Hong Kong com um grupo de jovens budistas sobre suas crenças e práticas religiosas. Nessa investigação, avaliaram as predições para o desenvolvimento futuro da religiosidade dos budistas jovens. Mostraram as especificidades de uma formação budista, comparando-as às cristãs. Para os autores, o uso do termo orientação religiosa budista tem conotações próprias, e não ficaram claras suas características.

Feitas, em periódicos, esta breve revisão dos conceitos abordados, a partir de agora, o artigo apresenta novos pontos de pesquisa a partir de leis.

\section{Incluindo uma pesquisa parcial de leis e documentos esclarecedores: Declaração Universal dos Direitos Humanos, Lei de diretrizes e Bases, Constituição Brasileira e Estatuto da Criança e do Adolescente}

No final da II Guerra Mundial, o mundo acolheu a Declaração Universal dos Direitos Humanos (1948) que tem valor de afirmação de uma "ética universal" e por isso manterá seu lugar de símbolo ideal. No seu artigo 26, inciso II diz “ Os pais tem prioridade de direito na escolha do gênero de instrução que será ministrada a seus filhos". Aqui, incluímos a protagonização dos pais/mães também na definição do ensino de valores religiosos e espirituais aos filhos. Com sua atualidade renovada, esse 'símbolo ideal' de organização social fortalece a direção dos nossos argumentos. 
Já no nosso pais, após o fim do Regime Militar (1964-1985) foi promulgada a Lei de Diretrizes e Bases da Educação Nacional (1996). Na LDB n.9394 ficou estabelecido que "o ensino religioso, de matrícula facultativa, será parte do currículo escolar público"(artigo 33). Mas, que ensino religioso é este? Quem escolhe a formação dos professores? É um ensino religioso confessional ou interconfessional? Que lugar ocupam os pais, mães e responsáveis familiares na decisão assim posta?

Para nós, o conceito de ensino religioso confessional é aquele baseado nos valores de uma religião e interconfessional nos valores ecumênicos, de várias religiões.

A partir da LDB conflitos tem sido vivenciados pelo ensino público e, pode -se dizer, por boa parte da classe educacional brasileira. Como demonstram as ADI - Ação direta da inconstitucionalidade do artigo 33 da LDB. Essas foram registradas pela Confederação Nacional dos Trabalhadores em Educação e outra pela Procuradoria Geral da República. Estes questionamentos de dispositivos do artigo 33 da LDB aguardam julgamento do STF- Supremo Tribunal Federal. Consideramos que os dois proponentes das ADI são representativos senão da maioria, pelo menos de boa parte dos educadores brasileiros

Mais diretamente ligada ao fim da Ditadura no país, temos a atual Constituição da República Brasileira (1988), também reconhecida como Constituição Cidadã, por objetivar a emancipação da sociedade brasileira pós longo período de regime militar. Essa Carta Magna foi além do arcabouço político-administrativo do Estado e erigiu princípios norteadores das atividades do Estado. Como exemplo a garantia de acesso universal à educação e à saúde. Entretanto, também abrigou como herança a LDB, já aqui citada.

No texto introdutório está registrado que “(...)para instituir um Estado Democrático (...) direitos sociais e individuais, a liberdade, a segurança, o bem-estar, o desenvolvimento, a igualdade e a justiça como valores supremos de uma sociedade fraterna pluralista e sem preconceitos (...)promulgamos, sob a proteção de Deus(...)"

A introdução da Constituição não é normativa, pois a Carta Magna é composta sob a forma de artigos que aparecem a seguir a esse texto. Justo aqui está a invocação da "proteção de Deus" para que o documento máximo do país trilhasse a direção de uma "sociedade fraterna".

Aqui destacam -se dois conceitos religiosos, sendo a Constituição Republicana 
laica ou não religiosa.

No artigo $1^{\circ}$ diz que a dignidade da pessoa humana é fundamento da República e confere amplitude ao foco da meta do desenvolvimento humano.

No artigo $3^{\circ}$ afirma que são objeto fundamental da República construir uma sociedade solidária e sem preconceitos, o que inclui a religião.

Já no artigo $5^{\circ}$ normatiza que todos são iguais perante a lei, sem distinção de qualquer natureza, garantindo-se aos brasileiros e aos estrangeiros residentes no País a inviolabilidade do direito à vida, à liberdade, à igualdade, à segurança e à propriedade. Seguem-se os parágrafos VI e VII que tratam da liberdade de consciência e crença, com livre exercício dos cultos religiosos.

Ao reunir os trechos citados da Constituição (1988) pode-se concluir que o fundamento constitucional da dignidade humana abrange o elemento espiritual como patrimônio imaterial e inviolável componente da nossa espécie, objeto de investimento da República para fins do desenvolvimento rumo à fraternidade e a Paz.

No mesmo sentido de harmonia com a Constituição (1988) a Lei 8.069/90 que organizou e instituiu o ECA (1990) - Estatuto da Criança e do Adolescente, preceitua que a noção de dignidade humana envolve o dever de investimento por parte da família, da comunidade e do Estado no desenvolvimento físico, mental, moral, espiritual e social de crianças e adolescentes, sem discriminação de religião ou crença.

No artigo $3^{\circ}$ encontra -se que a criança e o adolescente gozam de todos os direitos fundamentais inerentes à pessoa humana sem prejuízo da proteção integral de que trata esta lei, assegurando-se- lhes, por lei ou por outros meios, todas as oportunidades e facilidades, a fim de lhes facultar o desenvolvimento físico, mental, moral, espiritual e social, em condições de liberdade e de dignidade.

Reunindo as reflexões sobre a Constituição Nacional (1988), o Estatuto da Criança e Adolescente (1990), a Declaração Universal dos Direitos Humanos encontramos coerência com as análises feitas no presente artigo. Todos apontam na direção do que chamamos de ecologia espiritual, isto é, orientação espiritual 'com' crianças e jovens com desenvolvimento de valores universais da ética, da moral, da dignidade humana que são os valores de uma espiritualidade cidadã.

Concluída esta revisão parcial dos conceitos abordados, o artigo passa a apresentar o campo em estudo do CEBUDV, ou simplesmente UDV, União do Vegetal, 
suas pesquisas na área e seus desdobramentos.

Apresentando o campo da pesquisa no CEBUDV e seus desdobramentos: No CEBUDV - Centro Espírita Beneficente União do Vegetal, ou simplesmente UDV, onde foi feita a pesquisa qualitativa citada, essa não é a primeira investigação realizada. Em 2001, já havia sido feita uma investigação com jovens que frequentam as sessões rituais nessa sociedade religiosa, que faz uso ritualístico do Chá Hoasca. Um grupo de cientistas da Universidade da Califórnia - UCLA e da Universidade Federal de São Paulo - UNIFESP foram os responsáveis pela investigação. Esse trabalho teve como objetivo principal avaliar a saúde física e mental de um grupo de jovens da instituição, e indicar se o consumo ritual do Chá por longo prazo teria prejudicado seu desenvolvimento. Participaram como grupo controle estudantes do Colégio Arquidiocesano da cidade de São Paulo. Doering, Silveira et al., 2011; Silveira et al., 2011), Rios et al., 2011.

Os resultados, publicados no Journal of Psychoactive Drugs em 2005, evidenciaram que os adolescentes da UDV apresentavam desenvolvimento físico e mental semelhante ao do grupo de comparação, e sugeriram que o consumo ritual da Hoasca poderia ter um efeito protetor contra o abuso de drogas na adolescência. Ainda mais, que os jovens da UDV tendiam a valorizar princípios éticos em geral e tinham melhor relacionamento com os pais, em relação ao grupo de comparação. Na conclusão de uma das publicações, os autores afirmaram que: "não encontraram evidências dos efeitos prejudiciais da ayahuasca em adolescentes que participam com suas famílias de rituais cerimoniais" (Grob, C.S \& Silveira 2005a, b, c; Grob, C.S. e Rios, M.D. et al 2005).

Após esta pesquisa, somente em 2009-2010 foi feita nova investigação qualitativa no mesmo campo, porém com objetivos diferentes, que é este estudo que inspira o artigo. Na fase preliminar da pesquisa, foram enviados 301 questionários a 26 núcleos da UDV. Foram estudadas 173 (57,6\%) narrativas de voluntários entre 18 e 35 anos, que passaram a infância e/ou adolescência na instituição. Dos resultados encontrados, destacamos aqui a necessidade de mais integração entre pais, filhos e instituição. Também uma certa confusão entre os conceitos de ensino religioso e orientação espiritual com criança e adolescente. (Motta et al,2011:384-390)

Paralelamente à revisão bibliográfica para este artigo, foram feitos vários 
encontros com pais e responsáveis por este trabalho na UDV, em diferentes regiões do país, no sentido de refletir a respeito dos resultados da pesquisa, gerando novos projetos educacionais. Nesses encontros com pais e responsáveis, perguntas foram feitas, desenvolvendo a necessidade de novas investigações, além de mudanças já em implantação nos Núcleos. Uma significativa mudança sugerida foi a mudança do nome GTER - Grupo de Trabalho de Ensino Religioso para OEUDV - Orientação Espiritual com Crianças e Jovens da União do Vegetal.

Essa mudança foi feita e referendada pelos administradores do CEBUDV (UDV). A partir deste ponto, estão sendo trabalhados novos projetos que visem maior envolvimento dos dirigentes e a formação/preparação dos pais e mães, no sentido de assumirem, cada vez mais, a centralidade do trabalho. Desta maneira, os dois principais resultados da fase I da pesquisa - maior aproximação entre pais/mães, filhos e instituição e o clareamento dos conceitos - estão contemplados e em movimento no projeto atual da instituição.

\section{Refletindo os dados do artigo à título de conclusão:}

Concluímos que o interesse na dimensão espiritual ou religiosa na formação da identidade individual e grupal traduz um reconhecimento da importância desse aspecto humano como decisiva contribuição à saúde-educação das crianças, adolescentes e jovens. Concordamos com artigo 26, inciso II, da Declaração Universal dos Direitos Humanos (1948) que diz: os pais/mães/responsáveis tem "prioridade de direito na escolha do gênero de instrução que será ministrada a seus filhos"

Retornando o início do artigo e a pergunta central concluímos que:

- A denominação de Ensino Religioso confessional se refere à proposta de trabalho de um grupo centrado na transmissão de conceitos específicos de uma religião, com metodologia própria do grupo. Que o ensino religioso é um trabalho direcionado para crianças e adolescentes visando à transmissão de valores religiosos, que requerem a crença como condição para sua compreensão. Que o ensino religioso confessional visa continuidade da tradição através da crença, do dogma, sem necessariamente ter como meta a reflexão.

- A denominação de Orientação Espiritual é conceituada como princípio ético da fraternidade humana, das relações do ser humano com a natureza, no sentido de uma 
ecologia espiritual, isto é, do reconhecimento pelo homem de que a natureza é obra divina, que aqui é tomada como base para construção ativa das relações cidadãs de Paz. Que o desenvolvimento da espiritualidade inclui um sentido de vida norteador para as crianças, adolescentes e jovens como uma das dimensões básicas na formação do caráter cívico.

- É importante ressaltar que a proposta feita neste artigo é de Orientação Espiritual com Criança, com Adolescentes e com Jovens. Aponta para uma metodologia de construção dialogal e lúdica entre adultos e crianças/adolescentes/jovens. E, tem a meta de formação de uma consciência reflexiva, capaz de ter argumentos opinativos. A visão espiritual pretende proporcionar a ampliação do nível de consciência, propiciando o olhar introspectivo sobre si mesmo, para com o outro e com o meio em geral. Como consequência a formação de um sentido de vida. Diferente do ensino religioso confessional, não inclui a crença como pressuposto de inclusão. Considera os pais/mães/responsáveis familiares como protagonistas no trabalho de orientação espiritual com os filhos, sempre que possível. As instituições educacionais, religiosas, sociais deverão se manter como auxiliares dos pais/mães/responsáveis familiares. Para isso o trabalho institucional deverá ser desenvolvido em conjunto com pais/mães/famílias.

- $\quad$ Com as considerações acima e com base na leitura feita de pontos da Constituição Brasileira (1988); da Declaração Universal dos |Direitos Humanos (1948); do Estatuto da Criança e Adolescente (1990); da Lei de Diretrizes e Bases da Educação Nacional (1996, art. 33) consideramos que a polêmica em curso no STF - Supremo Tribunal Federal sobre ensino religioso confessional ou interconfessional nas escolas públicas é uma prioridade a ser analisada. Vemos o STF como um "guardião da Constituição" que não está restrito a esfera jurídica, mas definidor de políticas públicas. É, também um palco de visibilidade para um tema social de tal importância. Pensamos que o Estado não pode discriminar ou privilegiar uma religião. Não deve beneficiar, promover uma religião em detrimento de outras. Tem a obrigação de tolerar a fé alheia ou a não fé. A responsabilidade do STF será definir uma política pública educacional que auxilie a nação educar cidadãos conscientes e participativos na construção de um mundo melhor e menos desigual para todos.. 


\section{Referências}

ARNDT, B., AXEL F.-M., JENNIFER G. and HEUSSE, P. Aspects of spirituality in adolescents (2010). International Journal of Children's Spirituality,15, (1), 25-44 February.

AVEST, K.H. Dutch children and their 'God': the development of the 'God 'concept among indigenous and immigrant children in the Netherlands (2009). British Journal of Religious Education Vol. 31, No. 3, 251-262, September.

BETHANY, O. and QI WANQ (2008). Children's spiritual development in forced displacement: a human rights perspective. International Journal of Children's Spirituality, 13, (2), 129-143, May.

DOERING-SILVEIRA et al. (2011) Ayhuasca na adolescência; um estudo s respeito da saúde e comportamento de adolescentes usuários de Hoasca em contexto ritual. Bernardino- Costa e Silva (org). Hoasca: ciência, sociedade e meio ambiente. Campinas: Ed. Mercado das Letras.

EMILE, D.E.S.P. (2008) Pastor Emile's children. International Journal of Children's Spirituality. 13 (3) 235-239, August.

FREATHY, R., AYLWARD, K. (2010) Everything is in parables: "An exploration of students' difficulties in understanding Christian beliefs concerning Jesus. UK: Religious Education, 105 (1), January-February.

FREIRE, P.; FAÚNDEZ, A. (1985) por uma pedagogia da pergunta. Rio de Janeiro. Paz e Terra.

GIUMBELLI, E. (2008) A presença do religioso no espaço público: modalidades no Brasil. Religião e Sociedade, 28(2): 80-101. Rio de Janeiro.

GROB, C.S. e RIOS, MD et al. (2005) Ayahuasca in adolescence: qualitative results. Journal of Psychoaticive Drugs, 37(2),135.

GROB, C.S. e SILVEIRA, D.X. (2005) Ayahuasca in adolescence: a neuropsychological assessment. Journal of Psychoaticive Drugs, 37(2),123.

GROB, C.S. e SILVEIRA, D.X. (2005) Ayahuasca in adolescence: a preliminary psychiatric assessment. Journal of Psychoaticive Drugs, 37(2), 141.

GROB, C.S. e SILVEIRA, D.X. (2005) Reports on psychoactive drug use among adolescents using ayahuasca Within a religious context. Journal of Psychoaticive Drugs, 37(2),129.

GUSTAV, K.K. YEUNG, G.K.K.; CHOW, W.Y. (2010) 'To take up your own responsibility': the religiosity of Buddhist adolescents in Hong Kong. International Journal of Children's Spirituality, 15 (1), 5-23, February.

HODDER, J. (2009) Spirituality and well-being: 'New Age' and 'evangelical' spiritual expressions among young people and their implications for well-being. International Journal of Children's Spirituality 14, (3), 197-212, August

MIRANDA, J. (2010) Convivendo com o diferente com o "diferente": juventude carismática e tolerância religiosa. In: Relig. E Sociedade, 30 (1):117-142, Rio de Janeiro.

MOTTA, J.C. (2002) Jogos: repetição ou criação? Abordagem psicodramática. São Paulo. Ed. Ágora.

MOTTA, J.C.; Neves, E.S.; Almeida, E.M.; Rodrigues, J. (2011) Narrativa na vida adulta da vivência de orientação religiosa na infância e na adolescência. In: Brasília Med, 48(4):384-390

PIRES, F. (2010). Tornando-se adulto: uma abordagem antropológica sobre as crianças e religião. Religião e Sociedade, 30(1) 143-164.

RAISUYAH BHAGWAN (2009) Creating sacred experiences for children as pathways to healing, growth and transformation. International Journal of Children's Spirituality. 14, (3), 225-234. August. 
RIOS, M. D. et al. Ayhuasca na adolescência: resultados qualitativos. In: Bernardino- Costa e Silva (org). Hoasca: ciência, sociedade e meio ambiente. Campinas: Mercado das Letras.

SAGBERG, S. (2008) Children's spirituality with reference to a Norwegian context: some hermeneutical reflections. International Journal of Children's Spirituality, 13 (4), 355-370. November.

SILVEIRA, D.X. et al. (2011) Ayhuasca na adolescência: uma avaliação psiquiátrica preliminar. Bernardino- Costa e Silva (org). Hoasca: ciência, sociedade e meio ambiente. Campinas: Ed. Mercado das Letras.

STURLA SAGBERG (2008) Children's spirituality with reference to a Norwegian context: some hermeneutical reflections. International Journal of Children's Spirituality 13 (4), 355370. November.

\section{Obras consultadas}

BHAGWAN, R. (2009) Creating sacred experiences for children as pathways to healing, growth and transformation. International Journal of Children's Spirituality, Vol. 14, No. 3, 225234, August.

BRITO, G (2002). Farmacologia humana da Hoasca (chá preparado de plantas alucinógenas usado em contexto ritual no Brasil. In: Labate, B e Araujo, W. (orgs.) O uso ritual da Ayahuasca. Campinas: Mercado das Letras; São Paulo: FAPESP, 577-604.

BUSSING, A., FOLLER-MANCINIA, A., GIGLEY, J., HEUSSER, P. (2010) Aspects of spirituality in adolescents. International Journal of Children's Spirituality, 15, (1), 25-44, February.

CEBUDV (1994). Consolidação das leis do Centro Espírita Beneficente União do Vegetal, $3^{\mathrm{a}}$ ed. Sede Geral. Brasília.

CESCON, E. Resenha de Dennett, D. (2008) Breaking the Spell: é a religião um fenômeno natural? Religião e Sociedade, 28(2)210-220, Rio de Janeiro.

FISHERMAN, S. (2008) Identity and intimacy in religiously observant and non-religiously observant adolescents and young adult in Israel. Religious Education,103, (5), OctoberDecember.

GENTIL L. e GENTIL H. (2002) O uso de psicoativo em um contexto religioso: a União do Vegetal, in LABATE, B.C. e ARAUJO, W.S. (orgs), O uso Ritual da Ayahuasca. Campinas: Mercado das Letras.

GENTIL, L.: NEVES, E.S. Histórico do processo de formação do Departamento Médico e Científico e da Comissão Científica. In: Bernardino-Costa, J. (org.) Hoasca: ciência, sociedade e meio ambiente. Campinas: Mercado das Letras, 2011.

MILANEZ, L.F. Objetivos e procedimentos da Comissão Científica da UDV (2011). In: Bernardino- Costa e Silva (org). Hoasca: ciência, sociedade e meio ambiente. Campinas: Ed. Mercado das Letras.

MOTTA, J.C., GENTIL1, L. (2011) Memórias: Uma breve narrativa baseada no acervo de depoimentos com mestres da origem da União do Vegetal - UDV In: Bernardino-Costa, J. (org.) Hoasca: ciência, sociedade e meio ambiente. Campinas: Mercado das Letras.

OJALEHTO, B., WANG, Q. (2008) Children's spiritual development in forced displacement: a human rights perspective. International Journal of Children's Spirituality. 13, (2), 129143.May.

PEREIRA, O.C.C. (2011) Hoasca na adolescência: Um estudo a respeito da saúde e comportamento de adolescentes usuários de Hoasca em contexto ritual. In: Bernadino-Costa, J. Hoasca: ciência, sociedade e meio ambiente. Campinas: Mercado das Letras. 
SAM-PEAL, E.D.E. (2008) Pastor Emile's children. International Journal of Children's Spirituality 13 (3), 235-239. August.

SEWELL, L. Evoking children's spirituality in the reciprocal relationships of a learning community. International Journal of Children's Spirituality, 14 (1), 5-16, February.

BACHAND, S.C. (2010) Living God or Cosmic therapist? Implications of the national survey of youth and religion for Christian religious education. Religious Education, 105 (2), MarchApril.

BONE, J. (2008) Exploring trauma, loss and healing: spirituality, Te Wham arc riki and early childhood education. International Journal of Children's Spirituality, 13 (3), 265-276, august.

BOSACKI, S.; ELLIOT, A.; AKSEER, S.; BAJOVIC, M. (2010) The spiritual component of children's lives: the role of media. British Journal of Religious Education, 32 (1), 49-61 January.

CHAMPAGNE, E. (2008) Living and dying: a window on (Christian) children's spirituality. International Journal of Children's Spirituality, 13 (3), 253-263, August.

EAUDE, T. (2009) Happiness, emotional well-being and mental health - what has Children's spirituality to offer? International Journal of Children's Spirituality, 14 (3), 185196. August.

ERICKSON, D.V. (2008) Spirituality, loss and recovery in children with disabilities. International Journal of Children's Spirituality, 13 (3), 287-296 August.

FISHER, J.W. (2009) Getting the balance: assessing spirituality and well-being among children and youth. International Journal of Children's Spirituality, 14 (3) 273-288. August

GROB, C.S. et al (2002) Farmacologia humana da Hoasca: efeitos psicológicos. In: Labate, B.; Araujo, W. (orgs.) O uso ritual da Ayahuasca. Campinas: Mercado das Letras; São Paulo: FAPESP, 605-630.

GROB, C.S.; SILVEIRA, D.X. (2005) Ayahuasca in adolescence: a preliminary psychiatric assessment. Journal of Psychoactive Drugs, 37(2), 129-134.

GROB, C.S., SILVEIRA M D. (2005) et al. Ayahuasca in adolescence: a neuropsychological assessment. Journal of Psychoactive Drugs, 37(2), 123-128.

GROB, C.S., SILVEIRA, D.X. et al. (2005) Reports on psychoactive drugs use among adolescents ayahuasca within a religious context. Journal of Psychoactives Drugs, 37(2), 141146.

GROB, C.S. RIOS, M. et al. (2005) Ayahuasca in adolescence qualitative results. In Journal of Psychoactive Drugs, 37(2), 135-140.

HYDE, B. (2008) The identification of four characteristics of children's spirituality in Australian Catholic primary schools. International Journal of Children's Spirituality, 13 (2) 117-127.

IPGRAVE, J. (2009) The language of friendship and identity: children's communication choices in an interfaith exchange. British Journal of Religious Education, 31 (3), 213-225, September.

KIRMANI M.H.; KIRMANI, S. (2009) Recognition of seven spiritual identities and its implications on children. International Journal of Children's Spirituality 14 (4), 369-383, November.

NAESLUND, L. The young and the other: students 'voices about encounters with faith. Religious Education, 104 (2), March-April.

NELSON, C. (2008) We are all affected: considering the recovery of HIV/AIDS infected and affected children. International Journal of Children's Spirituality, 13 (3) 203-211, 203-211. 
ROBERTS, R., BIREVICCACUT, M., BAKER, T. (2009) Children's understanding of the war in Iraq: views from Britain and Bosnia. International Journal of Children's Spirituality, 14 (1), 17-30, February.

SANTOS, R.G. (2010) The pharmacology of ayahuasca: a review, Brasilia Médica. Revista da Associação Médica de Brasília. 47, (2), 187-194, Brasília.

THOMAS, T.H. (2008) Spiritual practices children understand: an analysis of Madeleine L'Engle's fantasy, A Wind in the Door. International Journal of Children's Spirituality, 13 (2), 157-169. May.

WALTERS, D. A. (2008) Grief and loss: towards an existential phenomenology of child spirituality. International Journal of Children's Spirituality, 13 (3), 277-286.August.

WEBBER, R.; SINGLETON, A., JOYCE, M.R.; DORISSA, A. (2008) Models of youth ministry in action: The dynamics of Christian youth ministry in an Australian city. Religious Education, 105 (2) March-April.

Recebido: 19/10/2017

Received: 10/19/2017

Aprovado: $23 / 11 / 2017$

Approved: 11/23/2017 